\title{
The Effects of Rapid Strength and Shooting Training Applied to Professional Basketball Players on the Shot Percentage Level
}

\author{
Seyfi Savaş ${ }^{1}$, Mehmet Fatih Yüksel ${ }^{2}$, Ahmet Uzun ${ }^{2, *}$ \\ ${ }^{1}$ Sport Sciences Faculty, University of Gazi, Ankara, Turkey \\ ${ }^{2}$ Ahmet Keleşoğlu Faculty of Education, University of Necmettin Erbakan, Konya, Turkey
}

Copyright $\bigcirc 2018$ by authors, all rights reserved. Authors agree that this article remains permanently open access under the terms of the Creative Commons Attribution License 4.0 International License

\begin{abstract}
The aim of this study is to examine the effects of explosive strength and shooting exercises, which were applied for eight weeks before the season in basketball sport branch, on shot percentage level of elite male basketball players. The study was conducted on 13 professional male basketball players (age average; $26.92 \pm$ 3.04) who are actively playing in the Turkish Basketball Super League. The players were taken into pre-season camp for 12 weeks. At the end of the first four weeks, shooting tests (pre-tests) were applied to the players. Through the last eight weeks of the camp, condition improving practices were continued together with technique-tactic exercises. Through the last eight week of the camp explosive strength exercise program was applied covering 75-80 \% of the condition exercise with a frequency of 4-6 times a week. After the explosive strength exercises, shooting exercises (a total of 100 shots in 5 sets, each set 20 shots) were conducted. At the end of the eight-week camp period, the pre-season tests were repeated (post-tests). The shooting tests of the players (pre-tests and post-tests) were conducted in two different numbers and under three different formats, which are, standing free throw, jump shot, and jump shot against defense (1x1). Each player was told to shoot 100 shots in the first test and 10 shots in the second. Totally 8580 shots were analyzed in pre-tests and post-tests. SPSS 18.0 program was used in the analysis of the data, and the significance level was accepted as $p<0.01-0.05$. In both shooting tests, it was determined that there was a statistically significant difference in $p<0.01$ level between the average values of pre-tests and post-tests under three formats (standing free throw, jump shot, and jump shot against (1x1) defense). According to the data obtained from the study, it can be concluded that eight-week explosive power exercises have a positive effect on shooting performances particularly at their positions in the game of elite male basketball players.
\end{abstract}

Keywords Basketball, Rapid Strength, Shot

\section{Introduction}

When the characteristic features of basketball sport are considered, it seems that the main motoric traits are the frontal [1]. However, it is difficult to link success to a single criterion [2]. The most basic element that makes up the score is shoot, as well as basic motor skills. Shoot is the most important and frequently used technical movement among the physical skills applied in the play [3]. Players' shoot performances are required to be improved to win the match as well [4]. A certain strength and endurance is needed to shot the ball which is crucial for winning the match. Rapid strength training is also very important for basketball and is often used [1,5]. While rapid strength gaining work is applied; the basic principle is to make use of light and medium loads. It is particularly useful to have 40 to $60 \%$ of the maximal strength of the loading strength in the weight exercises to be applied [1].

When the literature is examined, it is seen that there are many researches conducted on physical fitness, strength and shooting in basketball at different age groups $[3,6,7,8$, $9,10,11,12,13]$. It has been reported that as the physiological and anatomical maturation is completed in the athletes of the professional level, the differences of the motor characteristics decrease [14]. It is also determined that the shooting performance percentages of the winning teams in man to man and team attack are high. The most important reason for this situation is that the players challenge their opponents in order to score more shots despite the maximal defensive pressure in man to man and team defenses [15]. Man to man defense is the mostly used defensive method used in 2 points zone by both the winning and losing teams $[16,17]$ and more than $50 \%$ of the winning teams uses man to man defense method [16].Therefore, it is considered to be important to combine shooting trainings with quick-strength trainings, and 
especially to investigate how shooting performance of professional level players is affected.

The purpose of this study is to examine the effect of rapid strength and shoot trainings applied for the eight weeks before the start of the season in the field of basketball sport to the shoot percentage level of elite male basketballers.

\section{Materials and Methods}

The study has been conducted on 13 men (mean age, $26.92 \pm 3: 04$ ) basketball players of Usak Sporty Sports Club, who are actively playing in Turkey Basketball Super League. Basketball players were taken to the camp for 12 weeks during the pre-season preparation period. In the first 4 weeks out of 12 weeks camping time, more conditioning workouts and especially long-run conditions where the aerobic energy path is more dominant, and continuity type training on the strength have been conducted. At the end of the four-week training session, shooting tests have been applied to the players (pre-test). During the last 8 weeks of the camp, along with technical-tactical training, condition improving trainings have been continued. Quick strength training program has been applied weekly 4-6 times so as to form $75-80 \%$ of the fitness training coverage in this process. Following quick-strength training, each athlete performed 20 shots ( 1 set) and 100 shoots in the nature of 5 sets per day and 400-600 shoots per week from the appropriate positions for the position that each athlete takes part in the play was in during the game. 2 minutes between the sets was given during shooting performance. At the end of the 8-week period, the pre-season shooting tests (post-test) were repeated with the end of the camp period.

The shooting tests (pre-test and post-test) applied to the players were carried out in two different numbers and three different conditions. Each player has ensured to make 100 shooting trial in the first shoot test and 10 shoot trial in the second shoot test. The 10-shoot test was conducted considering that a player had an average of 8-10 shooting attempts in a basketball game. 100 shoot tests have been applied to ensure the validity and reliability of the data obtained without working. Free shoot by standing, leapfrog shoot and leapfrog shooting (1x1) against defense have been applied in three different conditions. It was necessary to explain two important points about the method of our work. It was necessary to explain two important points about the method of our work. While the test protocol was being developed, it was ensured to consist of defense player, who is attempting shoot and taking part in the same position in the play, in leapfrog shoot (1x1) test against defense. The second point is that the players were asked to shoot from the regions they were attempting to shoot, due to the position that the players take part in the play in all the shooting tests. In determining the players' positions, the positions they played in the general character of the game are taken into account. It is known that today's basketball is directly related to especially high percentage shoot and the region in which it is used and by whom it is used. In addition, it is thought that it is important to determine accurate shoot as a statistic in the regions where the players have used the most shoots in the play; no limit is imposed on the place to be shooting in the execution of the shoot test. However, especially players who are called as pivots and are in position 5 in the play are required to attempt to shoot at a distance of a medium distance from the basket. In the pre-test and post-test, a total of 8580 shots were analyzed

Two separate protocols have been implemented in rapid-strength training. Studies have been carried out on 6 movements determined by medicine balls and bar-dumbbells, in the form of circular training by using the repeat method in Program-1. Whereas, pyramidal method was used in Program-2 and studies were carried out on 4 movements for the purpose of weight machines. 1 RM test was performed to determine the kgs that the players should lift, and the training programs applied are given below.

\section{Program 1}

Objective: Rapid Strength

Method: Repetition Method

Table 1. Weightlifting exercise program in Program-1

\begin{tabular}{|c|c|c|c|c|c|}
\hline & \multirow{2}{*}{ Intensity } & \multirow{2}{*}{$\begin{array}{c}\text { Number } \\
\text { of Sets }\end{array}$} & \multirow{2}{*}{ Time } & \multicolumn{2}{|c|}{ Interval Time } \\
\hline & & & & Between Moves & Between Sets \\
\hline Lying Triceps Extension & $\begin{array}{l}\% 50-60 \\
(15-20 \mathrm{~kg})\end{array}$ & $4-6$ & $20 \mathrm{sec}$ & $1 \mathrm{~min}$ & $4-5 \mathrm{~min}$ \\
\hline Vertical jump with bar & $\begin{array}{l}\% 50-60 \\
(25-30 \mathrm{~kg})\end{array}$ & $4-6$ & $20 \mathrm{sec}$ & $1 \mathrm{~min}$ & $4-5 \min$ \\
\hline Leg raising with medicine ball & $\begin{array}{l}\% 50-60 \\
(5 \mathrm{~kg})\end{array}$ & $4-6$ & $20 \mathrm{sec}$ & $1 \mathrm{~min}$ & $4-5 \min$ \\
\hline $\begin{array}{l}\text { Lying in Hyperextension with medicine } \\
\text { ball }\end{array}$ & $\begin{array}{c}\% 50-60 \\
(5 \mathrm{~kg})\end{array}$ & $4-6$ & $20 \mathrm{sec}$ & $1 \mathrm{~min}$ & $4-5 \min$ \\
\hline $\begin{array}{c}\text { Alternate front arm raising and Lateral } \\
\text { dumbbell raising }\end{array}$ & $\begin{array}{l}\% 50-60 \\
(2 \times 5 \mathrm{~kg})\end{array}$ & $4-6$ & $20 \mathrm{sec}$ & $1 \mathrm{~min}$ & $4-5 \min$ \\
\hline $\begin{array}{l}\text { Vertical jumping with bar on vaulting } \\
\text { boxes }\end{array}$ & $\begin{array}{c}\% 40-60 \\
(15-20 \mathrm{~kg}) \\
(\text { height: } 30 \mathrm{~cm})\end{array}$ & $4-6$ & $20 \mathrm{sec}$ & $1 \mathrm{~min}$ & $4-5 \min$ \\
\hline
\end{tabular}




\section{Program 2}

Objective: Rapid Strength

Method: Pyramidal Method

Table 2. Weightlifting exercise program in Program-2

\begin{tabular}{|c|c|c|c|c|c|}
\hline & & Half Squat & Bench Press & Standing Calf & Lat Pulldown \\
\hline \multirow{4}{*}{\multicolumn{2}{|c|}{ Intensity and Repetition }} & $12 \times \% 40$ & $12 \times \% 40$ & $12 \times \% 40$ & $12 \times \% 40$ \\
\hline & & $10 \times \% 45$ & $10 \times \% 45$ & $10 \times \% 45$ & $10 \times \% 45$ \\
\hline & & $8 \times \% 50$ & $8 \times \% 50$ & $8 \times \% 50$ & $8 \times \% 50$ \\
\hline & & $6 \times \% 60$ & $6 \times \% 60$ & $6 \times \% 60$ & $6 \times \% 60$ \\
\hline \multicolumn{2}{|c|}{ Number of Sets } & $3-5$ & $3-5$ & $3-5$ & $3-5$ \\
\hline \multirow{2}{*}{ Interval Time } & Between Moves & $1 \mathrm{~min}$ & $1 \mathrm{~min}$ & $1 \mathrm{~min}$ & $1 \mathrm{~min}$ \\
\hline & Between Sets & $4-5 \mathrm{~min}$ & $4-5 \mathrm{~min}$ & $4-5 \min$ & $4-5 \min$ \\
\hline
\end{tabular}

\section{Statistical Evaluation}

SPSS 18.0 program was used in the analysis of the data, and minimum, maximum, arithmetic mean, and standard deviation values of measurements and tests were determined. "Wilcoxon T Test" was used in order to determine the differences between the values of pre-tests and post-tests and the significance level was accepted as $\mathrm{p}<0.01-0.05$.

\section{Results}

Table 3. Physical features of the participants

\begin{tabular}{|cccccc|}
\hline & N & Minimum & Maximum & Mean & Std. Deviation \\
\hline Age & & 23.00 & 32.00 & 26.9 & 3.00 \\
Stature & \multirow{2}{13}{} & 178.00 & 208.00 & 196.6 & 9.8 \\
Body weight & & 73.00 & 118.00 & 94.4 & 13.5 \\
BMI & & 22.48 & 27.36 & 24.3 & 1.7 \\
\hline
\end{tabular}

Of the elite male basketball players who participated in the research, the average age was determined as 26.9 , average stature $196.6 \mathrm{~cm}$, average body weight $94.4 \mathrm{~kg}$, and average body mass index was determined as $24.3 \mathrm{~kg} / \mathrm{m}^{2}$.

Table 4. 100-shot test results of the basketball players.

\begin{tabular}{|c|c|c|c|c|c|c|c|c|c|}
\hline Variables & & $\mathbf{N}$ & $\begin{array}{c}\text { Number of } \\
\text { Shots }\end{array}$ & Mean & Min & Max & $\mathbf{Z}$ & $\mathbf{p}$ & $\%$ Difference \\
\hline \multirow{2}{*}{$\begin{array}{c}\text { Standing free } \\
\text { throw }\end{array}$} & Pre-test & \multirow{2}{*}{13} & \multirow{2}{*}{100} & $78.3 \pm 5.8$ & 68.00 & 87.00 & \multirow{2}{*}{2.91} & \multirow{2}{*}{, $004^{* *}$} & \multirow{2}{*}{6.4} \\
\hline & Post-test & & & $83.3 \pm 5.4$ & 76.00 & 93.00 & & & \\
\hline \multirow{2}{*}{ Jump shots } & Pre-test & \multirow{2}{*}{13} & \multirow{2}{*}{100} & $72.7 \pm 4.3$ & 67.00 & 80.00 & \multirow{2}{*}{2.90} & \multirow{2}{*}{, $004^{* *}$} & \multirow{2}{*}{6.18} \\
\hline & Post-test & & & $77.1 \pm 3.7$ & 71.00 & 82.00 & & & \\
\hline \multirow{2}{*}{$\begin{array}{c}\text { Jump shot } \\
\text { against defense } \\
1 \times 1\end{array}$} & Pre-test & \multirow[t]{2}{*}{13} & \multirow[t]{2}{*}{100} & $63.2 \pm 3.6$ & 59.00 & 71.00 & \multirow[t]{2}{*}{2.85} & \multirow[t]{2}{*}{, $004^{* *}$} & \multirow[t]{2}{*}{5.37} \\
\hline & Post-test & & & $66.6 \pm 3.4$ & 62.00 & 73.00 & & & \\
\hline
\end{tabular}

${ }^{* *} \mathrm{P}<0.01$

${ }^{*} \mathrm{P}<0.05$

Considering the 100-shot tests of the elite male basketball players participated in the research, it was determined that there was statistically significant difference $(\mathrm{P}<0.01)$ between pre-tests and post-tests with regards to standing free throw, jump shots, and jump shot against defense (1x1). 
Table 5. 10-shot Test results of the basketball players.

\begin{tabular}{|c|c|c|c|c|c|c|c|c|c|}
\hline Variables & & $\mathbf{N}$ & $\begin{array}{c}\text { Number of } \\
\text { Shots }\end{array}$ & Mean & Min & Max & $\mathbf{Z}$ & $\mathbf{p}$ & $\%$ Difference \\
\hline \multirow{2}{*}{$\begin{array}{l}\text { Standing free } \\
\text { throw }\end{array}$} & Pre-test & \multirow{2}{*}{13} & \multirow{2}{*}{10} & $8.6 \pm 1$ & 7.00 & 10.00 & \multirow{2}{*}{1.027} & \multirow{2}{*}{,305 } & \multirow{2}{*}{4.65} \\
\hline & Post-test & & & $9 \pm 0.6$ & 8.00 & 10.00 & & & \\
\hline \multirow{2}{*}{ Jump shots } & Pre-test & \multirow{2}{*}{13} & \multirow{2}{*}{10} & $6 \pm 0.7$ & 5.00 & 8.00 & \multirow{2}{*}{2.950} & \multirow{2}{*}{, $003^{* *}$} & \multirow{2}{*}{36.6} \\
\hline & Post-test & & & $8.2 \pm 1.4$ & 5.00 & 10.00 & & & \\
\hline \multirow{2}{*}{$\begin{array}{c}\text { Jump shot } \\
\text { against defense } \\
1 \times 1\end{array}$} & Pre-test & \multirow[t]{2}{*}{13} & \multirow[t]{2}{*}{10} & $6 \pm 0.7$ & 5.00 & 7.00 & \multirow[t]{2}{*}{2.667} & \multirow[t]{2}{*}{, $008^{* *}$} & \multirow[t]{2}{*}{16.6} \\
\hline & Post-test & & & $7 \pm 1.2$ & 5.00 & 9.00 & & & \\
\hline
\end{tabular}

Considering the 10-shot tests of the elite male basketball players participated in the research, it was determined that there was statistically significant difference $(\mathrm{P}<0.01)$ between pre-tests and post-tests with regards to jump shots and jump shot against defense (1x1), while there was no statistically significant difference with regards to standing free throw $(\mathrm{P}>0.05)$.

\section{Discussion and Conclusions}

This study has been carried out to examine the effect of rapid strength and shoot trainings applied for the eight weeks before the start of the season in the field of basketball sport to the shoot percentage level of elite male basketballers. An increase of 5.98\% was observed, in the average of the three shoot tests performed in three conditions in the first shoot test after the applied exercises, and while an increase of $19.28 \%$ was observed in the second shoot test.

It has been reported that extra shoots in the basketball have a positive effect on players' shoot hitting percentage $[3,18]$. In addition, make a pass and dribble techniques have been reported to have a positive effect on each other $[12,19]$. There is an increase in the number of correct shots per year. In the NBA, the free-throw hit rate in the $1999-2000$ season rose from $74.1 \%$ to $75.91 \%$ in the 2009-2010 season and the 3-point shot to $35.3 \%$ from $34.1 \%$ [3] in November 2006 Toronto changed their shooting coach and Dave Hope came to club as the shooting coach because of the low percentage of the team's shooting, and in February 2007 the team's 2-point shooting percentage was $44.2 \%$ that increased to $47 \%$, While the percentage of 3 -point shots percentage increased from $30 \%$ to $40 \%$ [20]. In 2010 World Basketball Championship for the semi-finalists (United States, Turkey, from Serbia, Lithuania) shooting average free throw 70.33\%, 2-point $\%$ 54.68 and 3-pointer, while $39.75 \%$ in the championship rankings in the last 4 teams ( Canada, Tunisia, Iran, Ivory), the shot average was $68.33 \%$ for free throw, $41.78 \%$ for 2 points and $28.58 \%$ for 3 points [3] . Circular strength training and shooting practice covering rapid strength principles for 6 weeks being 3 days a week for improving the muscles that helps to shoot in 16-17 year old male basketball players. At the end of the study, it was determined that the percentage of the shoots improved by $10,22 \%$. It can be said that the improvement of percentage of shoot on target is similar to the study carried out. In addition, it has been seen that the percentage of shoot on target of young basketball players shows more improvement compared to the 1st Shooting test consisting of 100 shooting attempts. However, it has been determined that the percentage of shoot on target is higher than that of young basketball players. This can be explained by the fact that the experimental group in the study was professional basketball players. It can also be said that the differences between the leagues are also influenced in the ratio of shoot on target.

In another study conducted on the shot, the effect of fatigue on shoot performance was examined. At the level of fatigue created by the $20 \mathrm{~m}$ shuttle running test protocol, it is stated that moderate and high intensity fatigue was a significant effect on the players' shoot performance [8]. It is known that a certain strength and endurance are required to shoot. In parallel to this, exercises applied in program-1 and program-2 consists of rapid strength improving exercises in the study carried out. In other studies on basketball players, the effects of core region training and terabant training on the shooting performance were examined [12, 13]. Despite the fact that no shooting training was carried out in both studies, statistically significant differences were found in shooting rates on target of basketball players. The studies carried out leaves from the study in terms of none of shoot training exercise, it can be said that the strength exercises similar to the training for the strength development in the present study also have a positive effect on the shoot performance and support the study conducted. It is reported that there is a positive contribution to the vertical jump height of the lower extremity force and the duration of reaching to this point, therefore shooting performance [21]. 6 out of 10 different exercises were performed specifically for the lower extremities in repetitive and rapid training programs applied with a pyramidal method in a similar study, and increases have been seen in the shoot performances of basketball players. 
The shoot is the most basic skill of basketball. At the same time, it is a skill that can be practiced alone and in which the training can recycle [3]. 12 female basketball players aged 13-14 participated in the study of the effect of the star drill shooting on the development of the shooting performance. Female basketball players were divided into 2 groups and both had a general basketball training session for 6 days in a week for 1 month. The experimental group also had a star shooting practice consisting of 100 shots every day. At the beginning of the training sessions and at the end of the training, three preliminary tests and final tests were conducted and the correct shots of both were calculated. As a result of 1-month training in the study, the control group increased the number of correct shots by only 6 in the average of the last 3 games, while the training group increased the number of shots by 59 [22]). The effect of increasing defensive press on shooting accuracy level is shown in the study in which the analyses of 2 and 3 points shooting performances were carried out for both winning and losing teams in a total of 3344 shoot trials in order to investigate the effects of defensive pressure on shooting performance in basketball. As a result of the study it is indicated that the most important difference between winning and losing teams is that the ability of the winning team to score under the high pressure of man to man defense. It is also stated in the study that the successful shooting percentages of the attack players under defensive pressure are 54,4\% in low level (112 shooting trials), 29,6\% in moderate level (61 shooting trials) and $16 \%$ in high level (33 shooting trials) [15].

As a result of the developments in the science of training, it is known that the quality of the different training methods is increased and thus reflected in the physical performance. It is possible to talk about the fact that during the competition, percentage of shoot on target of the players with advanced motor skills can increase along with extra shoot trainings. Obtaining data revealed in the studies from the basketball players at the highest level of Turkey basketball league and with full participation can be regarded as a powerful feature of the study. However, it is thought that it would be useful to evaluate this study-like study with a narrower scope for more reliable results, with higher participant and different league levels.

As a result of the study, it was determined that 8-week rapid-strength and shoot training positively affected the shoot performances of male basketball players in the elite level. It is known that the clubs struggling in the upper leagues especially have camp programs before and during the season. The realization of shooting exercises as well as condition improving training programs in the training programs applied in the pre-season camps and improving the shooting performance of the player are thought to be important. It may be advisable to protect the performance of the shoot before the season, along with the shooting trainings they will make during the season.

\section{REFERENCES}

[1] Sevim, Y. Antrenman Bilgisi, Nobel Yayınevi, Vol. 1, No.358, Ankara, 2002.

[2] Gocentas, A., Landõr, A., Andziulis, A. Dependence of intensity of specific basketball exercise from aerobic capacity: Papers on Anthropology, No.13, 9-17, 2004.

[3] Uzun, A., ve Pulur, A. Effect Of Free-Throw Training Program On Improving Shoot Hit Rate In Young Basketball Players (14-15 Years Of Age): Journal of Physical Education and Sport Science, Vol.5, No.2, 81-89, 2011.

[4] Fraizer, W. C., Sachare, A. The Complete Idiot's Guide to Basketball. Indianapolis: Alpha Books and Penguin Group Publishers, 1998.

[5] Bompa, T., Di Pasquale, M., \& Cornacchia, L. Serious strength training: Human Kinetics, 2003.

[6] Gürpınar, B., Sözeri, B., Tuncel, F., \& Erol, E. The Effects of Explosive Strength Training on the Jump-Shoting Percentages of Male Basketball Players Aged 16-17: Gazi Journal of Physical Education and Sports Sciences, Vol.14, No.3, 3-12, 2009.

[7] Kilınç F., Erol A. E., \& Kumartaşl1, M. The effects of combined technics training on some physical strength and technical features that is applied to basketball players: International Journal of Human Sciences, Vol.8, No.1, 213-229, 2011.

[8] Mülazımoğlu, O. The Impact of Fatigue on Shooting in Young Basketball Players: Selçuk Unıversıty Journal of Physical Education and Sport Science, Vol.14, Say1.1, 37-41, 2012.

[9] Menevşe, A. The Comparıson of Anaerobic Powers of Basketball Players Considering Their Player Positions: Journal of Sports and Performance Researches Vol.4, Say1.1, 33-37, 2013.

[10] Bakırcı, A. \& Kılınç, F. The effect of applied combıned trainıng in the preparatory periods on the performance level of the university basketball team: Inonu University Journal of Physical Education and Sport Sciences, Vol.1, Say1.2, 48-67, 2014.

[11] Küçük, H., Doğan, E., \& Taşmektepligil, M. Y. The Comparision of Selected Physiological of Basketball Players According to Their Playing Positions: Journal of İnstitute of Social Sciences, Say1.13, 65-71, 2014.

[12] Yüksel, O., Akkoyunlu, Y., Karavelioğlu, M. B., Harmanc1, H., Kayhan, M., \& Koç, H. The effects of Core Strenght Training on Balance and Shot Percantage on Male Basketball Players: Marmara University Journal of Sports Sciences, Vol.1, Say1.1, 49-59, 2016.

[13] Canl1, U. The effect of strength trainings by using theraband on the motor skills and shooting performance of basketball players: International Journal of Social Sciences and Education Research, Vol.3, Say1.2, 857-867, 2017.

[14] Macardle, W., Katch, F., \& Katch V. Exercise Physiology Energy, Nutrition and human Performance: Eighth Edition. Lippincott Williams and Wilkins, Baltimore, 2015. 
[15] Csataljay, G., James, N., Hughes, M. \& Dancs, H. Effects of defensive pressure on basketball shooting performance. International Journal of Performance Analysis in Sport, 13(3), 594-601,2013

[16] Alvarez, A., Ortega, E., Gomez, M.A. and Salado, J. Study of the defensive performance indicators in peak performance basketball. Revista de Psicologia del Deporte, 18, (Supplement), 379-384, 2009

[17] Gomez, M. A., Tsamourtzis, E. and Lorenzo A. Defensive systems in basketball ball possessions. International Journal of Performance Analysis in Sport, 6(1), 98-107, 2006

[18] Wooten, M., \& Wooten, J. Coaching Basketball Successfully, 3rd Edition, Human Kinetics Publishers, 2013.

[19] Brandao, E., Janeira, M., Cura, J., \& Cura, P. Relationship between tecnical skills and game performance in youth basketball players: Revista Portuguessa De Ciencias De Desporto, Vol.3, Say1.2, 121-171, 2003.

[20] Haefner J, Haefner J. Basketball Shooting Course \& Practice Çalışmas - Discover How to Improve Your Shooting Stroke and Become a Lights Out Shooter! 2011. Available from: URL: http://www.breakthroughbasketball. com/pr/btshooting.html:

[21] Struzik, A., Pietraszewski, B., \& Zawadzki, J. Biomechanical analysis of the jump shot in basketball: Journal of Human Kinetics, Vol.42, Say1.2, 73-79, 2014.

[22] Hanes A. Girls' Basketball And The Jump Shot: A Study Of The Effectiveness Of The Ten Point, 100 Shot, Star Jump Shootıng Training On Junıor High Girls' Game Shootıng Percentages. Type. USA: Marietta College. 2006. 